\title{
Design and Synthesis of Glycoside Inhibitors of Glioma and Melanoma Growth.
}

Isabel García-Álvarez, ${ }^{\dagger}$ Guillermo Corrales, ${ }^{\dagger}$ Ernesto Doncel-Pérez, ${ }^{\Psi}$ Ana Muñoz, ${ }^{\S}$ Manuel Nieto-Sampedro ${ }^{*}{ }^{\Psi}$ and Alfonso Fernández-Mayoralas. $*, \dagger$

${ }^{\dagger}$ Instituto de Química Orgánica General, CSIC, Juan de la Cierva 3, 28006 Madrid, Spain, ${ }^{\Psi}$ Hospital Nacional de Parapléjicos, SESCAM, 45071 Toledo, Spain, Instituto Cajal, CSIC, Avda. Doctor Arce 37, 28002 Madrid, Spain, and ${ }^{\S}$ Laboratorios FAES FARMA, SA, Alpedrete 24, 28045 Madrid, Spain.

\section{TABLE OF CONTENTS}

Table 1S: Elemental analyses of target compounds 
Table 1S: Elemental analyses of target compounds.

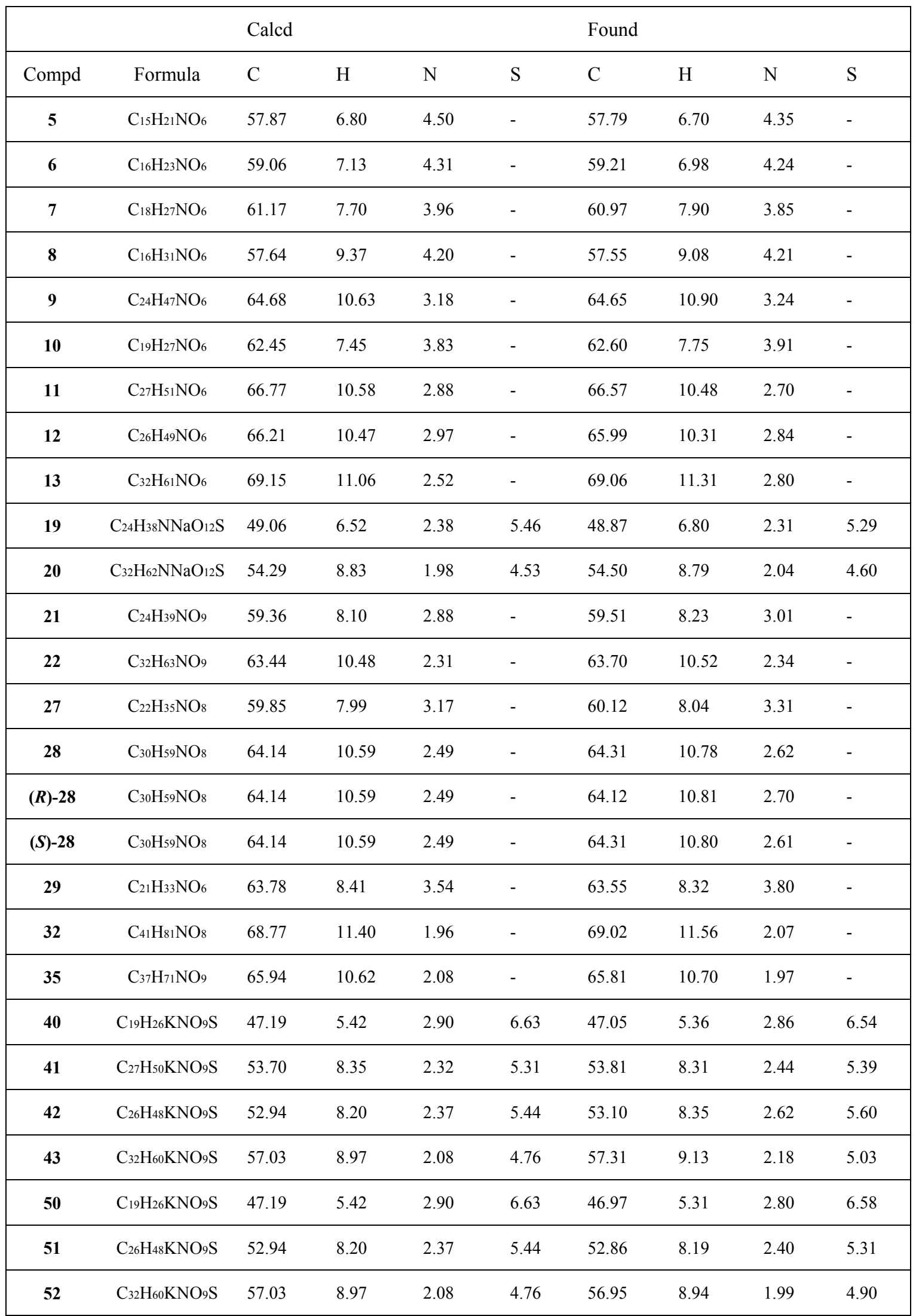

